\title{
Comparative study of different Al2O3: C dosimeters using OSL technique for dosimetry on Volumetric Modulated Arc Radiotherapy Treatment (VMAT)
} Estudo comparativo de diferentes dosímetros de Al2O3: C pela técnica OSL na dosimetria de tratamentos Radioterápicos por Arco Modulado Volumétrico (VMAT)

\author{
Daniel Villani ${ }^{1}$, Anselmo Mancini ${ }^{2}$, Cecilia M. K. Haddad ${ }^{2}$, Letícia L. Campos ${ }^{1}$ \\ ${ }^{1}$ Instituto de Pesquisas Energéticas e Nucleares - IPEN/CNEN, São Paulo, Brasil \\ ${ }^{2}$ Centro de Radioterapia, Hospital Sírio-Libanês, São Paulo, Brasil
}

\begin{abstract}
Resumo
Na radioterapia moderna, a técnica VMAT se tornou uma alternativa bem-sucedida de tratamento. Devido a sua complexidade, um programa de garantia de qualidade deve ser estabelecido, analisando, dentre outros, fatores dosimétricos. Este trabalho tem por objetivo comparar a performance entre os dosímetros OSL de óxido de alumínio $\left(\mathrm{Al}_{2} \mathrm{O}_{3}: \mathrm{C}\right)$ nanoDot ${ }^{\mathrm{TM}}$ (Inlight ${ }^{\mathrm{TM}}$ system) fabricados pela Landauer Inc. e dosímetros de $\mathrm{Al}_{2} \mathrm{O}_{3}: \mathrm{C}$ TLD-500 fabricados pela Rexon ${ }^{\mathrm{TM}}$ para dosimetria VMAT utilizando um simulador antropomórfico. Os resultados mostraram que ambos os tipos de dosímetros de $\mathrm{Al}_{2} \mathrm{O}_{3}: \mathrm{C}$ apresentam boa repetibilidade e concordância entre as doses medidas e calculadas pelo sistema de planejamento. Entretanto a necessidade de uma leitora sofisticada para análise OSL dos TLD-500, torna essa pastilha menos prática para aplicação rotineira, comparando com o Inlight ${ }^{\mathrm{TM}}$ system.
\end{abstract}

Palavras-chave: dosimetria OSL; VMAT; $\mathrm{Al}_{2} \mathrm{O}_{3}: \mathrm{C}$.

\begin{abstract}
In modern radiotherapy, the VMAT technique has become a successful treatment alternative. Due to its complexity, a quality assurance program must be established by evaluating, among other items, the dosimetric factors. This paper aims to compare the performance between the OSL aluminum oxide $\left(\mathrm{Al}_{2} \mathrm{O}_{3}: \mathrm{C}\right)$ nanoDot ${ }^{\mathrm{TM}}$ dosimeters (Inlight ${ }^{\mathrm{TM}}$ system) manufactured by Landauer Inc. and TLD-500 $\mathrm{Al}_{2} \mathrm{O}_{3}: \mathrm{C}$ dosimeters manufactured by Rexon ${ }^{\mathrm{TM}}$ for VMAT dosimetry using an anthropomorphic phantom. The results showed that both type of $\mathrm{Al}_{2} \mathrm{O}_{3}: \mathrm{C}$ dosimeters presented good repeatability and agreement between the doses measured and calculated by planning system. However, the need of sophisticated readers to OSL analysis of the TLD-500, turns it less practical for routine usage, comparing to Inlight ${ }^{\mathrm{TM}}$ system.
\end{abstract}

Keywords: OSL dosimetry; VMAT; $\mathrm{Al}_{2} \mathrm{O}_{3}: \mathrm{C}$.

\section{Introduction}

Radiation Therapy uses ionizing radiation for treating malignancies and seeks the extermination of tumor volume, exclusively or associated with other therapies. It has one of the most complex configurations in the health care sector, within equipment arrangement, technologies involved and it is still subject to major technological advances ${ }^{1-3}$. In addition to the curative effect, this type of treatment is also an effective option of palliation and symptom control in recurrent cancers or advanced stages, minimizing suffering and providing better quality of life for patients ${ }^{4}$.

In modern radiotherapy, many efforts are being invested to improve dose distribution lines, as well as the integration of imaging techniques for tracking tumors and correction of variations in between and intra fractions ${ }^{5}$. Among them, can be highlighted the Intensity-Modulated Radiation Therapy (IMRT), Stereotactic Radiation Surgeries (SRS), Volumetric Modulated Arc Therapy (VMAT), among others, all of them followed by image guidance.
The VMAT technique has become a successful treatment alternative. It works delivering intensitymodulated Radiation therapy (IMRT), also providing shaped formed beams, whereby the continuously-on fluence radiation is delivered with one or more rotations of the gantry of a linear accelerator equipped with Multileaf collimator (MLC), while the dose rate and gantry speed vary continuously,7. Comparative studies between IMRT and VMAT plans have presented that VMAT minimizes treatment time, reducing uncertainties associated with patient movement, and surround tissue toxicity ${ }^{8}$.

Due to its complexity, a quality assurance program must be established by evaluating, among other items, the dosimetric factors. The dosimetry of ionizing radiation is essential for the radiological protection programs, for quality assurance and licensing of equipment. The treatment planning and dose delivery verification is essential to maintain the integrity of patient treatments and equipment. Several organizations recommended maximum 
values range of $\pm 5 \%$ for the total uncertainty in dose delivering ${ }^{9,10}$.

The main type of dosimetry used in modulated radiotherapy dose verification is ionizing chambers $^{11}$. However, studies have proposed luminescent materials by TL and OSL techniques as efficient tools to this type of quality control. The Dosimetric Materials Laboratory of IPEN has been developing works related to clinical dosimetry of electrons and photons using LiF:Mg,Ti and $\mathrm{CaSO}_{4}: \mathrm{Dy}$ dosimeters ${ }^{12-14}$. The latest research of the Institute has involved the same dosimeters for IMRT and VMAT dosimetry ${ }^{15-18}$

The aluminum oxide $\left(\mathrm{Al}_{2} \mathrm{O}_{3}: \mathrm{C}\right)$ has provided good results as luminescent detector ${ }^{19}$. There are several ways of presenting dosimeters using aluminum oxide, as well as the readers needed to evaluate the OSL signal. Studies using $\mathrm{Al}_{2} \mathrm{O}_{3}: \mathrm{C}$ as OSL dosimeters been accomplished, however the number of published articles is small and the lack of established protocols and characterization of this OSLDs remain the main obstacle for its popularization in clinical dosimetry ${ }^{20}$.

In order to generalize the use of OSL dosimetry in radiotherapy, Landauer Inc. (Landauer, Inc., Glenwood, IL) has developed a simple and efficient commercial system for use in dosimetry OSL, known as Inlight ${ }^{\mathrm{TM}}$ system $^{21}$. The system, used for individual monitoring radiation protection, has been tested with radiotherapy dosimetry purposes with good results ${ }^{22,23}$. Rexon ${ }^{\mathrm{TM}}$ components and TLD Systems, less widespread, also produces $\mathrm{Al}_{2} \mathrm{O}_{3}: \mathrm{C}$ dosimeters (TLD-500) and reading systems. However, these pellets can be characterized with other readers ${ }^{24}$.

This paper aims to compare the performance between the OSL aluminum oxide nanoDot ${ }^{\mathrm{TM}}$ dosimeters (Inlight ${ }^{\mathrm{TM}}$ system) manufactured by Landauer Inc. and TLD-500 $\mathrm{Al}_{2} \mathrm{O}_{3}: \mathrm{C}$ dosimeters manufactured by Rexon ${ }^{\mathrm{TM}}$ TLD Systems for VMAT dosimetry using an anthropomorphic phantom.

\section{Material and Methods}

\subsection{Materials}

In this study, were used 25 nanoDot $^{\mathrm{TM}}$ dosimeters. The nanoDots are $5 \mathrm{~mm}$ diameter, $0.2 \mathrm{~mm}$ thick diskshaped $\mathrm{Al}_{2} \mathrm{O}_{3}: \mathrm{C}$, encased in a light-tight plastic with dimensions of $10 \times 10 \times 2 \mathrm{~mm}^{3}$. The samples were granted by SAPRA Landauer Serviços de Acessoria e Proteção Radiológica, representative of Landauer Inc. in Brazil.

It were also used $15 \quad \mathrm{Al}_{2} \mathrm{O}_{3}: \mathrm{C}$ TLD-500 dosimeters manufactured by Rexon ${ }^{\mathrm{TM}}$ TLD Systems. The TLD-500 dosimeters are $5 \mathrm{~mm}$ diameter and $0.9 \mathrm{~mm}$ thick. No plastic or specific covering for this dosimeters are supplied by manufacture, so in order to keep all dosimeters out of light during measurements, the pellets were protected using aluminum paper.

\subsection{Equipments}

For nanoDots readout, it was used the InLight ${ }^{\mathrm{TM}}$ System microStar ${ }^{\mathrm{TM}}$ reader, from Dosimetric Materials Laboratory - LMD/IPEN. It uses Light Emitting Diodes (LED) emitting light at a wavelength of $532 \mathrm{~nm}$ (green) as the light source of stimulation $^{21}$.

The TLD-500 were evaluated in a RIS $\varnothing$ TL/OSLDA-20 reader from LMD/IPEN. The reader was equipped with the standard PMT tube bialkali EMI 9235QB, $90 \%$ intensity of blue LED light source was used as OSL stimulation, and Hoya U-340 (7.5 $\mathrm{mm}$ thick, $45 \mathrm{~mm}$ diameter) filter.

\subsection{Irradiation Systems}

For preliminary performance tests, a $4 \pi$ geometry gamma source of ${ }^{137} \mathrm{Cs}$ (Activity of $38,11 \mathrm{GBq}$ in 17 April 2014) from LMD/IPEN, was used. All measurements were performed free in air at electronic equilibrium conditions.

For clinical dosimetry measurements, both dosimetric systems were calibrated using $6 \mathrm{MV}$ photon beam from a VARIAN ${ }^{\mathrm{TM}}$ NOVALIS TX at Sírio-Libanês Hospital (HSL). The characterization measurements were carried out within depth of maximum dose.

\subsection{Bleaching Treatment}

The optical annealing treatment for reutilization of the samples were fulfilled using a Ourolux ${ }^{\circledR}$ 1,3 watts of power lamp, composed of 30 blue LEDs.

\subsection{Methods}

The TLD-500 were selected according to their sensitivity and repeatability better then $\pm 5 \%$ to

${ }^{137} \mathrm{Cs}$. Each nanoDot comes with a labeled sensitivity. In effect, this value is a batch sensitivity similar to that used for TLD's. This factor depends upon the amount of dosimetric material $\left(\mathrm{Al}_{2} \mathrm{O}_{3}: \mathrm{C}\right)$ in each nanoDot. In radiation therapy, this is typically referred to as the repeatability of the device ${ }^{25}$. So, in order to "screen" the dosimeters and ensure that the OSL responses are all similar, they were also selected according to their sensitivity and repeatability better then $\pm 5 \%$ to ${ }^{137} \mathrm{Cs}$.

In clinical characterization, dosimeters were irradiated in a linear accelerator VARIAN ${ }^{\mathrm{TM}}$ NOVALIS TX at Sírio-Libanês Hospital (HSL) for $6 \mathrm{MV}$ photon beam, in the dose range from 25cGy up to 300 cGy using solid water SW phantom. Irradiations were carried out in depth of maximum dose, with set up field of $10 \times 10 \mathrm{~cm}^{2}$ and sourceskin distance (SSD) of $100 \mathrm{~cm}$.

An anthropomorphic phantom CIRS ${ }^{\mathrm{TM}}$, model Stereotactic End-to-End Verification "STEEV" was used to simulate a VMAT tumor treatment. This tissue equivalent phantom has a removable skull vertex that provides access to a rectangular brain cavity that receives interchangeable quality assurance (QA) and dosimetry inserts. This way, it is possible to simulate treatments throughout the 
region of head, brain and neck with greater anatomical rigidity and reliability.

The tumor volume to be treated with a VMAT planning was determined by one of manufacturer's $\mathrm{QA}$ inserts, which has a tumor tissue equivalent mass. This accessory has perfectly adjusted geometry for fitting tight into the phantom. In need to accommodate the dosimeters into this tumor volume, small molds of dental wax were developed to fix the dosimeters in the central position of the target volume. Figure $1 \mathrm{~A}$ and $\mathrm{B}$ shows the molds for nanoDots and TLD-500 respectively. Figure $1 \mathrm{C}$ shows 'STEEV' phantom with opened skull and QA inserts ready to be fitted together.

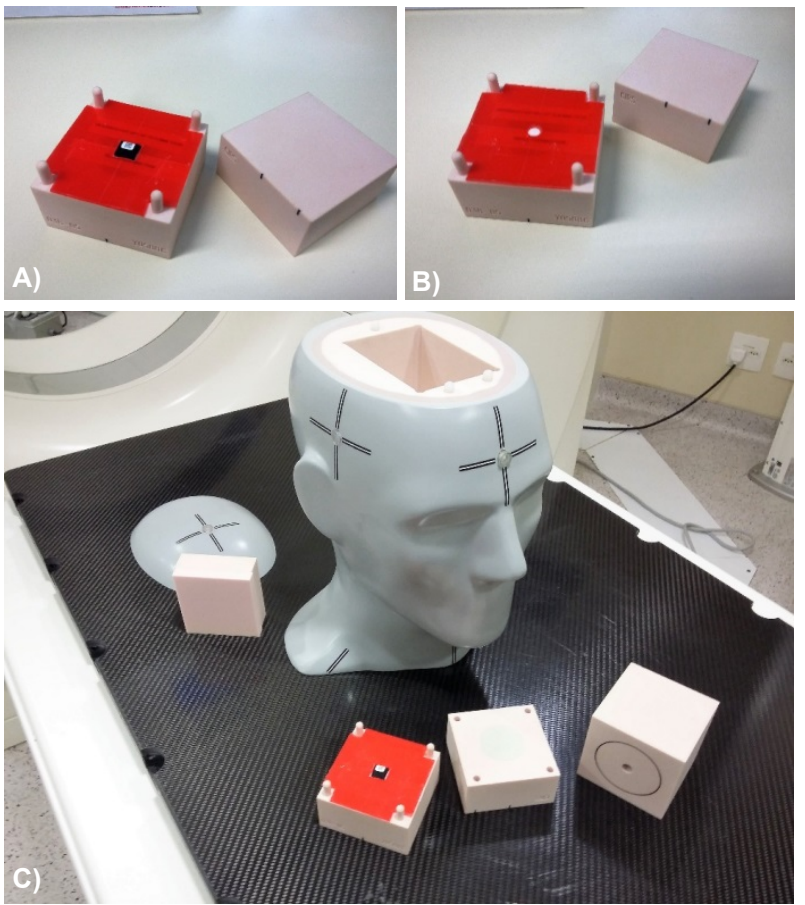

Figure 1. Details of phantom adjustments used. A) Mold of dental wax for accommodation on nanoDot dosimeters into the center of QA insert. B) Same type of mold for TLD-500

dosimeters. C) STEEV phantom with opened skull and $Q A$ inserts ready to be fitted together.

A Computer Tomography scan was performed for brain tumor treatment planning with eyeballs, chiasmus and brainstem protection (Figure 2). For VMAT planning it was used the Varian Eclipse ${ }^{\mathrm{TM}}$ 10.0 planning system, Varian RapidArc ${ }^{\mathrm{TM}}$ technology and Varian $A A^{T M}$ calculation algorithm. Considering the incentive to assess the dose with relatively small pellets, the grid resolution used in the calculation was $1 \mathrm{~mm}$.

After planning done, the treatment was delivered using nanoDots and TLD-500 dosimeters separately (Figure 3). This process was repeated five times to improve statistics to the research, and by the fact that it was possible to engage only one dosimeter at a time.

The irradiations were done in order to verify the performance of the $\mathrm{Al}_{2} \mathrm{O}_{3}: \mathrm{C}$ dosimeters and their agreement with VMAT Eclipse 10.0 planed treatment.

Each presented value of absorbed dose is the average of the five dosimeters measurements, and the error bars present the standard deviation of the mean. NanoDot read outs were carried out using microstar reader and response-to-dose calculations using microStar software.

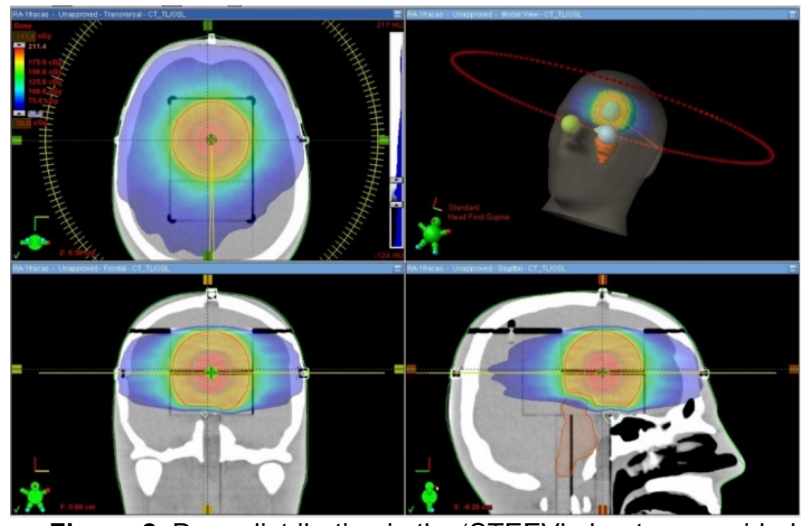

Figure 2. Dose distribution in the 'STEEV' phantom provided by Eclipse 10.0 planning system.

TLD-500 calculations were done with the Microsoft Excel 2016 software. The calibration curves were plotted, without showing the error bars when the experimental errors are smaller than the data points, using OriginPro 8.1, that also provided the fit curves and its parameters.

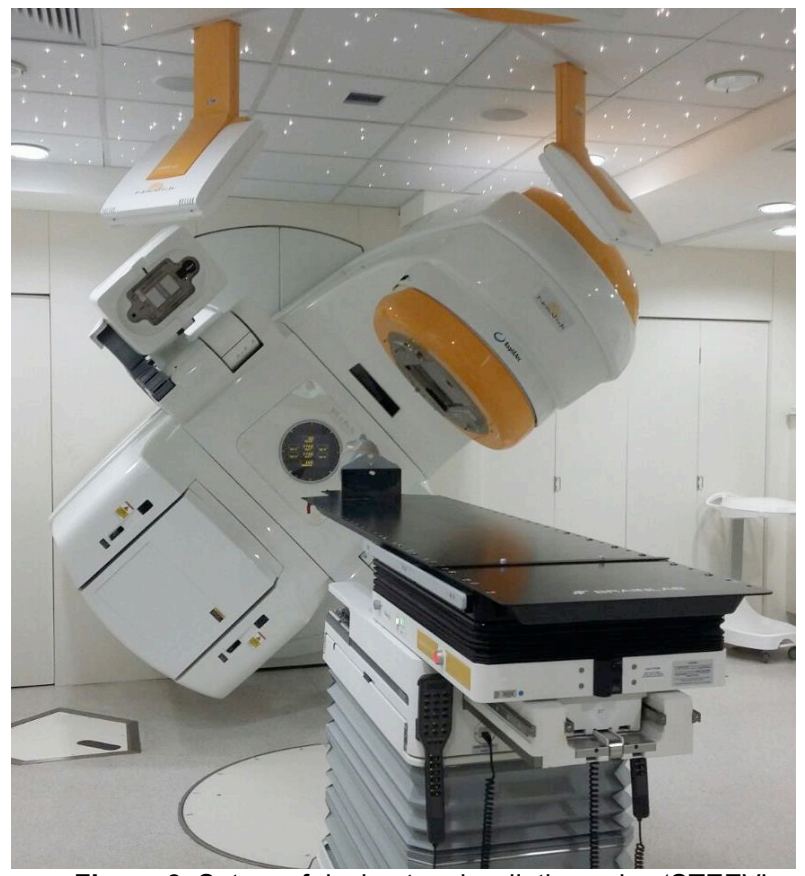

Figure 3. Set up of dosimeters irradiation using 'STEEV' phantom patient and linear accelerator VARIAN NOVALIS TX of HSL.

\section{Results}

The OSL dose-response curves for both $\mathrm{Al}_{2} \mathrm{O}_{3}: \mathrm{C}$ dosimeters to linear accelerator NOVALIS TX in the absorbed dose range from 25 up to 300 cGy are presented in Figures 4 and 5. This particular range was chosen by the linearity of response of both materials and for its applicability to radiotherapy using conventional fractionation (1.8 to 2.0 Gy per fraction). 
One can observe the expected linear behavior of OSL response of both type of dosimeters to the dose range studied.

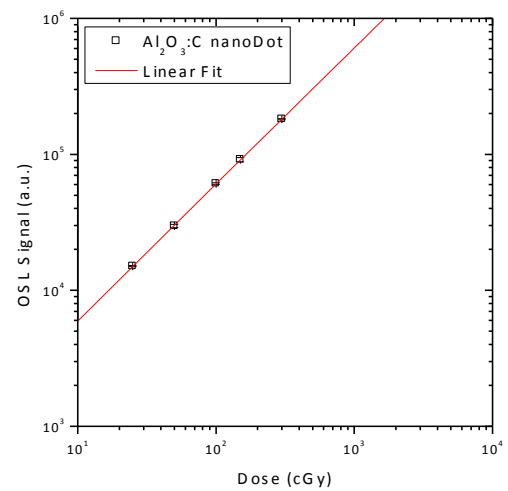

Figure 4. OSL dose-response curve of $\mathrm{Al}_{2} \mathrm{O}_{3}: \mathrm{C}$ nanoDot dosimeters to linear accelerator NOVALIS TX of HSL.

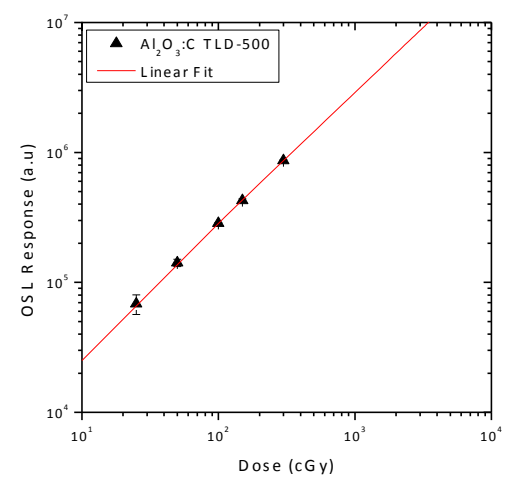

Figure 5. OSL dose-response curve of $\mathrm{Al}_{2} \mathrm{O}_{3}: \mathrm{C}$ TLD-500 dosimeters to linear accelerator NOVALIS TX of HSL.

Using the calibration factors obtained by the slope of both linear fitted curves, the maximum, minimum and average absorbed doses evaluated by $\mathrm{Al}_{2} \mathrm{O}_{3}: \mathrm{C}$ dosimeters are showed in Table 1 , along with Eclipse 10.0 calculated doses to dosimeters volume.

Table 1. Mean, Maximum and Minimum doses given by VMAT planning system and measured for $\mathrm{Al}_{2} \mathrm{O}_{3}: \mathrm{C}$ dosimeters volume.

\begin{tabular}{cccc}
\hline & \multicolumn{3}{c}{ Absorbed Doses (cGy) } \\
& $\mathbf{D}_{\text {mean }}$ & $\mathbf{D}_{\min }$ & $\mathbf{D}_{\max }$ \\
\hline Planning System & 203.7 & 202.4 & 205.8 \\
nanoDots & 204.2 & 201.6 & 205.5 \\
TLD-500 & 201.2 & 198.7 & 208.8 \\
\hline
\end{tabular}

The variation of maximum and minimum doses from Eclipse planning system show the homogeneity of planned delivered doses into dosimeters volume $\left(\sim 0,1 \mathrm{~cm}^{3}\right)$. The minimum and maximum values measured for the dosimeters show the variation in between the different measurements.

The deviation between the mean absorbed doses given by planning system and measured with $\mathrm{Al}_{2} \mathrm{O}_{3}: \mathrm{C}$ dosimeters was $+0.32 \%$ for nanoDots, and $-1.13 \%$ for TLD-500. The planning homogeneity and the agreement between the mean absorbed doses obtained with the $\mathrm{Al}_{2} \mathrm{O}_{3}: \mathrm{C}$ dosimeters are shown in Figure 5.

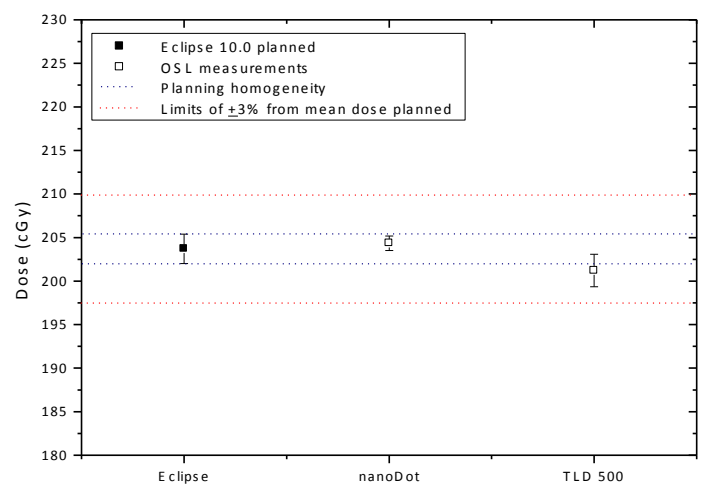

Figure 5. Planning homogeneity and the agreement between the mean absorbed doses obtained with the $\mathrm{Al}_{2} \mathrm{O}_{3}: \mathrm{C}$ dosimeters

\section{Discussion}

Though the analysis of Table 1 and Figure 5 , it can be noticed that the nanoDot measurements are fitted within the homogeneity of the planned treatment, and, despite a larger variation from TLD500 , all obtained values for this dosimeter vary less than $\pm 3 \%$ from the mean dose planned.

It can be notice as well the good accuracy and capability to characterize the OSL response of TLD-500 using the RIS $\varnothing$ TL/OSL reader. For nanoDots, the lower values on deviation of the mean, and deviation from mean doses planned can be explained by a possible better selection from manufacture, $\mathrm{Al}_{2} \mathrm{O}_{3}: \mathrm{C}$ production accuracy, and a great characterization among all the InLight System (nanoDots and microStar reader).

Other fact that can cause less dispersed values of absorbed dose is the considered absence angular dependence of OSL response of nanoDots to $6 \mathrm{MV}$ photon beam ${ }^{23}$, an unsure property of TLD-500. Further studies will be performed to add more repeatability and accuracy to OSL response of TLD-500 measurements.

\section{Conclusions}

The results showed that both type of $\mathrm{Al}_{2} \mathrm{O}_{3}: \mathrm{C}$ dosimeters presented good repeatability and agreement between the dose measured and the treatment planned prescribed doses by Eclipse. All uncertainties were within $\pm 2.5 \%$, so both techniques met the international performance requirements ${ }^{9,10}$.

However, the need of sophisticated readers to OSL analysis of the TLD-500 turns it less practical for its usage and routine application. In addition, due to its versatility, the InLight ${ }^{\mathrm{TM}}$ System (nanoDots and microStar reader) can be applied as a useful tool for dose verification in VMAT planning treatments and routine dosimetry.

\section{Acknowledgments}

The authors are thankful to CNEN, CNPq and FAPESP Process $n^{\circ} 2010 / 16437-0$ by the financial support; SAPRA Landauer by the samples, scientific and technical support; Radiation Therapy 
Center from Sírio-Libanês Hospital for the irradiations and LCI/IPEN for usage of the OSL laboratory.

\section{References}

1. Ford EC, Gaudette R, Myers L, Myers L, Vanderver B, Engineer L, et al. Int J Radiat Oncol Biol Phys. 2009;74:852858

2. Furnari L. Controle de qualidade em radioterapia. Revista Brasileira de Física Médica. 2009;3(1):77-90.

3. Teixeira FCS, Faria AL, Pereira DPS, Silva FMI. Análise qualitativa do risco no processo de tratamento em radioterapia para as etapas executadas pelo técnico/tecnólogo na radioterapia de intensidade modulada (IMRT). Proceedings of the IX Latin American IRPA Regional Congress on Radiation Protection and Safety IRPA 2013; 2013.

4. Barbosa PO. Implementação do controle de qualidade para sistemas de planejamento de tratamento em radioterapia nas avaliações locais do PQRT/INCA [Dissertação de Mestrado]. Rio de Janeiro: Instituto Alberto Luiz de Coimbra da Universidade Federal do Rio de Janeiro; 2011.

5. Broggi S. Cantone MC, Chiara A, Di Muzio N, Longobardi B, Mangili $P$, et al. Application of failure mode and effects analysis (FMEA) to pretreatment phases in tomotherapy. J Appl Clin Med Phys. 2013 Sep 6;14(5):265-77

6. Otto K. Volumetric modulated arc therapy: IMRT in a single gantry arc. Med Phys. 2008 Jan;35(1):310-7.

7. Webb S, McQuaid D. Some considerations concerning volumetric-modulated arc therapy: a stepping stone towards a general theory. Phys. Med. Biol. 2009;54;4345-60.

8. Verbakel WF, Cuijpers JP, Hoffmans D, Bieker M, Slotman BJ, Senan S. Volumetric intensity-modulated arc therapy vs. Conventional IMRT in head-and-neck cancer: a comparative planning and dosimetric study. Int J Radiat Oncol Biol Phys. 2009 May 1;74(1):252-9.

9. International Commission on Radiation Units and Measurements - ICRU. Report 24: Determination of Absorbed Dose in a Patient Irradiated by Beams of $X$ or Gamma Rays in Radiotherapy Procedures. Bethesda, Maryland: ICRU Publications, 1976.

10. American Association of Physics in Medicine. AAPM's TG51 protocol for clinical reference dosimetry of high-energy photon and electron beams. Med Phys. 1999;26(9):1847-70.

11. Low DA, Moran JM, Dong L, Oldham M. Dosimetry Tools and Techniques for IMRT. Medical Physics. Med. Phys. 2011 March;38(3):1313-38.

12. Nunes MG, Campos LL. Study of $\mathrm{CaSO}_{4}: \mathrm{Dy}$ and LiF:Mg,Ti detectors TL response to electron radiation using a SW Solid Water phantom. Radiat Meas. 02/2008; 43(s 2-6):45962.

13. Bravim A, Campos LL. Dosimetric evaluation of thermoluninescent $\mathrm{LiF}: \mathrm{Mg}, \mathrm{Ti}$ and $\mathrm{CaSO}_{4}$ :Dy dosimeters and LiF microdosimeters for application in in vivo dosimetry of clinical electron beams. Proceedings of the 2009 International Nuclear Atlantic Conference - INAC 2009; 2009

14. Matsushima LC, Veneziani GR, Sakuraba RK, Cruz JC, Campos LL. Response evaluation of CaSO4:Dy; LiF:Mg,Ti and LiF:Mg,Ti microdosimeters using liquid water phantom for clinical photon beams dosimetry. Radioprotecção (S. João da Talha) 2012;(2):205-12

15. Matsushima LC, Veneziani GR, Sakuraba RK, Cruz JC, Campos LL. Determination of the radiation dose scattered outside the target volume treated with IMRT technique. Radiation Measurements. 2014;(71):319-23.

16. Matsushima LC, Veneziani GR, Sakuraba RK, Cruz JC, Campos LL. TL and OSL dose response of LiF:Mg,Ti and $\mathrm{AL}_{2} \mathrm{O}_{3}: \mathrm{C}$ dosimeters using a PMMA phantom for IMRT technique quality assurance. Applied Radiation and Isotopes. 2015;(100):7-10.

17. Bravim A, Sakuraba RK, Cruz JC, Campos LL. Dose distribution assessment (comparison) in the target volume treated with VMAT given by the planning system and evaluated by TL dosimeters. Proceedings of the International Joint Conference RADIO 2014. 2014; Gramado: Proceed. International Joint Conference RADIO $2014 ; 2014$
18. Bravim A, Sakuraba RK, Cruz JC, Campos LL. OSL and TL response characterization of $\mathrm{LiF}: \mathrm{Mg}, \mathrm{Ti}$ microdosimeters to be applied to VMAT quality assurance. Applied Radiation and Isotopes, 2015 Nov;(105):299-302.

19. Sawakuchi GO, Yukihara EG, McKeever SWS, Benton ER. Optically stimulated luminescence fluence response of $\mathrm{Al}_{2} \mathrm{O}_{3}: \mathrm{C}$ dosemeters exposed to different types of radiation. Radiat. Meas. 2008;(43):450-54.

20. Yukihara EG, Gasparian PBR, Sawakuchi GO, Ruan C Ahmad S, Kalavagunta $C$, et al. Medical applications of optically stimulated luminescence dosimeters (OSLDs). Radiation Measurements. 2010;45(s 3-6):658-62.

21. Perks CA, Le Roy G, Prugnaud $B$. Introduction of the InLight monitoring service. Radiat. Prot. Dosim. 2007;125(14):220-3.

22. Viamonte A, da Rosa LA, Buckley LA, Cherpak A, Cygler JE. Radiotherapy dosimetry using a commercial OSL system. Med. Phys. 2008 Apr;35(4):1261-6.

23. Jursinic PA. Characterization of optically stimulated luminescent dosimeters, OSLDs, for clinical dosimetric measurements. Med Phys. 2007 Dec;34(12):4594-604.

24. Rexon.com [homepage on the Internet]. Rexon: Components \& TLD Systems Inc. [cited 2016 Apr 2]. Available from: http://www.rexon.com/.

25. Yahnke CJ. Calibrating the microStar. InLight Systems user manual;2009. Available from: http://www.landauer.com/.

\section{Contact:}

Daniel Villani

Comissão Nacional de Energia Nuclear, Instituto de Pesquisas Energéticas e Nucleares.

Avenida Professor Lineu Prestes, 2242 - Cidade Universitária.

05508-000 - São Paulo, SP - Brasil.

E-mail: dvillani@ipen.br 